\title{
¿SE PUEDE HABLAR DE EXTREMA DERECHA EN RUSIA?
}

Jean Meyer*

El25 de diciembre de 1991, el diario Izvestia publicó en primera plana: "en este día Rusia dejó de ser soviética y socialista". Dejó efectivamente de ser internacional-socialista. Ocho años después algunos se preguntan si Rusia no será algún día nacional-socialista y señalan con preocupación la existencia de numerosos grupos calificados de neo-nazis. Algunos otros que comparten la misma preocupación ven con asombro a los antiguos y a los neo-comunistas contaminados por el elemento nacionalista, así como el surgimiento de extrañas coaliciones entre nuevas derechas y viejas izquierdas: unión, bloque 'nacional-patriótico', 'nacional popular', 'popular patriótico', 'nacional-bolchevique'. La misma confusión evolutiva de las palabras señala la importancia y la duración de la crisis de identidad rusa. ¿Qué es Rusia? ¿Qué significa ser ruso? Rusia era un imperio, ¿quiere y puede ser una nación? Esas preguntas no surgen en tiempo de bonanza sino en momentos de crisis, cuando en las sociedades modernas el recurso al nacionalismo ha sido general. Raoul Girardet, especialista del nacionalismo francés, lo diagnosticó para la Francia derrotada y mutilada en 1870-1:

* División de Estudios Internacionales, Centro de Investigación y Docencia Económicas. 
JEAN MEYER

El nacionalismo es antes que nada un movimiento de defensa, de repliegue, de concentración sobre sí mismo de un cuerpo herido. Lo que quiere primero es levantar un dique, una mura1la. Frente a la presión o a las infiltraciones bárbaras, las fortificaciones no serán nunca lo suficientemente altas. Tiende a cuajar, a endurecerse (...) multiplica las exclusiones.'

La crisis de identidad abre la puerta a todos los delirios, a todas las patologías mentales, ideológicas, individuales ${ }^{2}$ y sociales. El campo político ofrece al analista un panorama que invita al estudio. El presente trabajo no es de ciencia politica, ni de sociologia, se sitúa más cerca de la historia de las ideas y de las pasiones.

Antes de presentar un cuadro del pequeño mundo agitado de las extremas derechas rusas, de analizar las visiones del mundo que las animan $y$, en una tercera parte, de evaluar la contaminación entre ellas y el papel que desempeñan los comunistas y los ortodoxos, quiero brevemente recordar la naturaleza de la crisis.

a) Para el observador exterior es dificil sentir lo que han vivido, lo que viven los rusos. Para muchos se trata de una derrota (Francia 1871, Alemania 1945, Japón 1945), pero una derrota incomparable e incomprensible porque no hubo una sola batalla, el edificio se derrumbó solo, desde adentro. Para muchos más es una quiebra; quiebra impe-

${ }^{1}$ Raoul Girardet, Le nationalisme francais, 1966, París, A. Colin.

${ }^{2}$ El 4 de noviembre de 1998, Iván Orlov, un jubilado de 65 años, provocó la explosión de su auto cerca de la entrada del Kremlin en Moscú. El atentado dejó tres heridos. El informe oficial menciona que "Orlov tiene tendencias esquizofrénicas". Ex-simpatizante del ultra-nacionalista Zhirinovski, Orlov es hoy integrante de un grupo comunista radical y escribe en la publicación Russkaya Pravda (DPA, AP, ANSA 5 de noviembre), semanario nacionalbolchevique, violentamente antisemita. Su título proviene de la obra del coronel Pablo Pestel, dirigente de la intentona golpista de diciembre de 1825 . Significa Justicia Rusa y es una utopía implacable, ortodoxa, centralista, militarizada. 
rial, económica, social. Rusia no tenía un imperio, como lo tuvieron Francia o Inglaterra, Rusia era un imperio. Ese problema, en cierta manera, lo sufrieron austríacos y turcos (y húngaros) en 1918, pero sin la dimensión ideológica comunista, y después del desastre militar. La crisis que culminó en diciembre de 1991 -hoy resulta fácil decirlofue la conclusión de viejos desequilibrios que no se tomaron en consideración. Para hablar como el difunto Andrei Siniavski, también conocido como Abraham Tertz, fue el error del 'totalitarismo de la pretensión'. Desde la muerte de Stalin (1953) hasta 1991 se habló siempre de los 'disfuncionamientos del régimen', nunca de la crisis del sistema. Por eso el acontecimiento tomó por sorpresa a los soviéticos que de pronto despertaron rusos, ukranianos, bielorusos... en el vacío. Frente a un inmenso e incomprensible acontecer, muchos abrazaron la teoría del complot para tener un elemento de racionalidad y, con ella, resucitaron los viejos fantasmas rusos. Rusia la fortaleza sitiada, el castillo de la pureza amenazado por los católicos, los polacos, los judíos, los caucasianos, los mongoles, los masones.

b) Por otra parte, la crisis de identidad es muy anterior al derrumbe de la Torre de Babel soviética. Ligada a la crisis del sistema soviético, remitía a la vez a una historia mucho más antigua, tan vieja como Rusia, la historia de un ciclo de crecimiento periódicamente cancelado por un brutal derrumbe ${ }^{3}$ del Estado. Así Rusia, hasta 1991, no ha conocido una historia acumulativa, 'progresiva' como Europa del Oeste o los Estados Unidos, sino un proceso de cambios radicales ligados a un modelo importado, seguidos por una etapa de estancamiento, liquidada a su vez por una ruptura violenta: la derrota engendra siempre la revolución brutal desde arriba.

Hoy los rusos deben moverse entre los enormes escombros de las estructuras políticas, socio-económicas y mentales del antiguo régimen. Viven una revolución (una más) encabezada por los mandos del

${ }^{3}$ Georges Sokoloff, La puissance pauvre, 1993, París, Fayard. Jean Meyer, Rusia y sus imperios, 1998, México, CIDE/FCE. 
JEAN MEYER

sistema difunto, lo que no deja de ser una paradoja. Apenas ahora empieza a surgir una generación de hombres nuevos pero no le toca aún la dirección real del Estado.

c) Abuso de la palabra 'crisis'; sin embargo, sería más correcto hablar de 'búsqueda' de una identidad. Esa búsqueda empezó en tiempos de Nikita Jrushchov cuando, en 1956, se atrevió a tocar al ídolo, Stalin. 40 años más tarde el presidente Yeltsin firmó un decreto ordenando, de manera tan ingenua como interesante, la búsqueda de una "idea nacional para toda la sociedad". Los trabajos de la comisión se perdieron en las arenas, pero mucha gente, a falta de la brújula 'socialista' orientada hacia el futuro, mira hacia el pasado para reencontrar a la grande, a la Santa Rusia, y encuentra a tres hombres fuertes, Stalin, Pedro el Grande, Ivan el Terrible.

El historiador de las ideas y de las representaciones colectivas no debería despreciar el desorden infructuoso del 'deshielo' de Jrushchov, menos aún el aparente 'estancamiento' de los años de Leonid Brezhnev. Antes de la perestroika, en tiempos de Brezhnev, las mentalidades se orientaron mucho hacia lo que se aproximaba a una 'so10 ciedad de consumo' socialista. Rehabilitaban poco a poco la llamada 'civilización campesina'; los 'escritores del campo' tuvieron éxito con su revista Nash Sovremennik (Nuestro Contemporáneo); un movimiento nacionalista de defensa del patrimonio arqueológico surgió para salvar templos y conventos amenazados por la violenta ofensiva antirreligiosa de Jrushchov; Ilyá Glazunov, como pintor histórico de la Santa Rusia conoció un enorme éxito que duró hasta 1991 y se apagó después, lo que no deja de ser interesante. ${ }^{5}$ Desde temprano algunos periodistas e ideólogos del partido comunista entraron en la ruta de una 'ideología nacional'; así la revista Molodaya Gvardia (Joven Guardia) se lanzó contra 'el Occidente podrido', celebrando en

${ }^{4}$ La novela de Friedich Gorenstein, La Place (la chamba, el lugar), 1991, París, escrita en 1972, es un testimonio muy valioso.

${ }^{5}$ Ilyá Glazunov, Tvorchestvo, 1991, Moscú, Poligrafii (álbum). 
Rusia 'la civilización del alma'. Después de la 'guerra de los seis días' (1967), la literatura soviética de propaganda pasó tranquilamente de ser antisionista - contra el Estado de Israel, a favor de los Estados árabes- a ser antijudía: Valeri Skurlatov daba el tono en el diario Moskovskii Komsomolets.

Para 1970 ya estaban presentes en círculos semi-oficiales todos los temas calificados hoy (1998) de nacional-bolcheviques. La recuperación, llevada a cabo por Stalin, de la patria, del pasado de la grandeza rusa, acompañada de la denuncia paralela de Trotski (David Bronstein, se insistía), abrió realmente la puerta a la tesis del complot occidental, judeomasón, para explicar todos los desastres del pasado. Y del futuro, después de 1988-1991. Caso admirable de profecía inconsciente que sus autores iban a usar para descifrar un presente por venir. Vale la pena notar que los primeros textos nacionalistas circularon, en los años 60, en 'samizdat', es decir clandestinamente, manuscritos, mecanografiados, exactamente como los textos de la oposición democrática. En 1970 circulaba un manuscrito anónimo Slovo natsii (La palabra de la nación) ${ }^{6}$ dirigido contra 'el programa del movimiento democrático'. De 1971 a 1973, Vladimir Ossipov publicó la revista Veche con el propósito de volver a las fuentes de la ideología nacional. Sus colaboradores eran moderados, excepto Ivanov. Resulta notable un artículo raro de Mijail Antonov que intenta conciliar ortodoxia y leninismo. Intento que prometía mucho en los 90.

d) En 1990 Rusia entró en la tempestad, tormenta comparada por aquellos que añoran el pasado a la smuta, el 'tiempo de los disturbios', cuando Rusia estuvo a punto de desaparecer después de las muertes de Ivan y de Boris Godunov a fines del siglo XVI y principios del siglo XVII. La violencia no faltó, ni falta: el domingo negro

${ }^{6} \mathrm{Su}$ autor era Anatoli Ivanov, que firmaba también Skurlatov y publicaba tanto en Moskovskii Komsomolets como en la revista Veche. Para esos años ver: Walter Laqueur, The Black Hundreds, 1993, New York y John L. H. Keep, The Last of the Empires, 1995, Oxford, capitulo 14, "The Russian national movement". 
JEAN MEYER

de Vilna en enero de 1991, el putsch fracasado de agosto del mismo año, las jornadas sangrientas de Moscú en octubre de 1993, la criminalidad desatada, la corrupción generalizada. $\mathrm{Y}$ todo ello poca cosa frente a la trágica guerra de Chechenia que costó cerca de 100,000 vidas (1994-1996), en su mayoría civiles, habitantes de la pequeña república del Cáucaso. Nada frente a la smuta de 1917-1920. Mucho para una sociedad acostumbrada durante más de 70 años a la mano de hierro del Estado y a su orden.

En el vacío político de esos años de duro aprendizaje surgió una gran corriente nacionalista, cambiante como camaleón y potencialmente rica de todos los excesos y de todas las vocaciones. Esto proviene de una idea tan simple, tan fuerte como el deseo, que consiste en que Rusia no puede ser sino una gran potencia (derzhava) y que por lo tanto necesita un gobierno fuerte y autoritario. Esta idea no es de derecha, ni de izquierda; hasta los demócratas, a veces, tienen esas nostalgias. Toda la vida política rusa se volvió nacionalista en los últimos años, empezando por el partido comunista. El presidente Yeltsin tardó un poco, dio el giro al sufrir la derrota en las elecciones legislativas de diciembre de 1993 que dio lugar a una mayoría nacional-bolchevique en la Duma, con el partido (liberal democrático) de Vladimir Zhrinovski y el PC dirigido por Evgueni Zyuganov. Esta mayoría hablaba de 'nashi', los 'nuestros', retomando un concepto de los ultranacionalistas de los años 1890-1914: los nuestros, los nacionalpatriotas, son los únicos buenos. Es también soviético el concepto de los 'otros', los agentes del extranjero, los instrumentos del complot contra Rusia. Este fenómeno se entiende como una reacción a la desintegración de la URSS, a la humillación, a la pérdida del estatuto de gran potencia. La presencia de problemas étnicos dentro de la Federación de Rusia (en el Cáucaso), la existencia de millones de rusos fuera de Rusia, de otros vecinos nacionalistas como los baltos, la desconfianza absoluta de todos los ex-vasallos de Europa central, todo ello empuja

${ }^{7}$ Anatol Lieven, Chechnya. Tombstone of Russian Power, 1998, Yale University Press. 
¿EXTREMA DERECHA EN RUSIA?

hacia la reacción nacionalista. Más aún cuando las condiciones no son muy favorables al desarrollo de ideas e instituciones democráticas: la palabra 'demócrata' se ha vuelto un insulto (como la de 'reformador'), como 'fascista' o 'judío'. Vale la pena notar que nadie acepta ser llamado 'fascista': en 1994 Zhirinovski demandó al reformador y demócrata que lo había llamado 'populista fascista'. Zhirinovski ganó su proceso contra Yegor Gaidar y el periódico Izvestia. Esto se debió a que la palabra 'fascista' remite a la segunda guerra mundial, epopeya rusa antes que soviética; de modo que en las mentes, en los corazones, el 'fascista' es el enemigo de la patria, no un derechista moderno y extremista.

\section{Las organizaciones}

Son numerosas, cambiantes, efimeras; se hacen y deshacen. Los mismos nombres se mueven en los organigramas, las rivalidades personales complican todo, el proceso permanente de fraccionalismo contradice el no menos permanente proceso de fusión. Asimismo, muchos grupos trabajan parcial o totalmente en la clandestinidad; no se puede excluir la acción y la manipulación de los servicios de seguridad del Estado. La cronología es incierta, la geografía dudosa, las cifras casi inexistentes. ${ }^{8}$

No cabe duda, existe una extrema derecha visible en Rusia, especialmente en las grandes ciudades. Un tiempo preocupó tanto a la corriente

${ }^{8} \mathrm{El}$ autor sigue el tema en la prensa rusa (y soviética) desde 1988. Además de los grandes títulos de la prensa moscovita, ha utilizado los semanarios Moskovskii Novosti y Russkaya Mysl. Los libros más útiles parecen ser: A. Verjovskii y V. Pribylovskii, Natsional-patrioticheskie organisatsii v Rossii. Istoriya, ideologuiya, extremistskie tendentsii, 1996, Moscú, de Institut Eksperimentalnoy sotsiologii. De los mismos con A. Papp, Politicheskii extremizm v Rossii, 1996, Moscú, Instituto de Sociología experimental. Centre Européen de Recherche sur le Racisme et l'Antisémitisme. Les extrémistes de l'Atlantique à l'Oural, 1996, París, 1'Aube. Datos actualizados en Stefan Woll, "Vash Kohl, tizhe evrei" (Su Kohl también es judío), Moskovskii Novosti, 1998, $\mathrm{n}^{\circ}$ 25, 28 de junio, p. 6-7. 
JEAN MEYER

democrática que el presidente Yeltsin, con un ojo sobre el Congreso europeo de Estrasburgo, firmó el 23 de marzo de 1995 un decreto contra el fascismo y 'otras formas de extremismo'. Curiosamente el mismo día salió de la cárcel (su estancia había sido muy breve) Alexei Vedenkin, ultraderechista, quien el 22 de febrero del mismo año, desde la pantalla de televisión, había amenazado con matar personalmente a sus dos colegas, los diputados Serguei Kovalev y Serguei Yushenkov, adversarios radicales de la guerra que tronaba en Grozny, la capital de Chechenia. $^{9}$

Se puede empezar con una presentación de la prensa radical, porque permite amontonar documentos, formar un archivo, armar un expediente; sin embargo, el investigador se topa con los problemas ya mencionados: breve duración, difusión imposible de evaluar, clandestinidad y, peor aún, una fundamental ambigüedad que permite leerla tanto como una prensa de extrema-derecha, como de extrema-izquierda. Esto no sucede siempre, pero sí es frecuente, lo que no deja de ser interesante como se verá en la tercera parte.

En reacción contra la perestroika surgió la corriente 'nacional-bolchevique', es decir, comunista, anticapitalista, caracterizada por un

14 nacionalismo ruso, un antisemitismo y un antisionismo muy marcados. Esa corriente fue y sigue siendo intelectual, sin llegar a las masas; cuenta entre sus publicaciones la ya mencionada revista Nash Sovremennik, otras como Moskva, Literaturnaya Rossia, Moskovski Literator, y el diario Sovietskaya Rossia. Como francamente nazis, podemos enumerar Al Kods, Press Rossii, Molodaya Gvardiya, Russkie Vedomosti, Russkie Vesti, Russkii Vostok, Soldat Udachi, Voljv. Más conocido es el periódico del escritor Eduard Limonov, Limonka (la gra-

${ }^{9}$ Moskovskii Komsomolets, 25 de marzo de 1995. E1 28 de octubre de 1994 el diario Izvestia había publicado una carta abierta al presidente Yeltsin, reclamando medidas contra los extremistas antidemocráticos. Serguei Kovalev era, aún, el valiente representante del presidente Yeltsin para la Defensa de los Derechos del Hombre. Había pasado varios días en Grozny, bajo los bombardeos rusos. 
nada); el periódico Shturmovik editado por Konstantin Kasimovski; ${ }^{10}$ y finalmente un diario con amplia difusión (a diferencia de todos los demás), Zavtra (Mañana), que se llamó Dien (el Día) hasta su suspensión en octubre de 1993, el cual tira 100,000 ejemplares.

¿Extrema derecha? ¿extrema izquierda? ¿pardirrojos? ¿fascistas? ¿nazis? ¿neo-? ¿post-?, ¿proto-? Poco importa. Hay que dejar esa labor a los taxonomistas. Si no puedo definir qué es, cuando me topo con esa literatura, con esa militancia, al menos la reconozco sin equivocarme. De la misma manera ellos dicen que no se pueden equivocar, que olfatean a un demócrata a 100 metros. Cuando Viktor Korchaguin incorpora 100 páginas de Mi lucha, de Adolfo Hitler, en su libro El proceso contra el académico Korchaguin, ${ }^{11}$ cuando la revista Molodaya Gvardiya publica en varias ocasiones capítulos enteros de los Protocolos de los Sabios de Sion, cuando el diario Zavtra hace lo mismo, no hay duda posible. Todos tienen en común un nacionalismo radical, racista, xenófobo, que invita al uso de la violencia para arreglar los problemas con el 'enemigo', interior primero, exterior después. Estos grupos niegan todos los valores democráticos y liberales. Simultáneamente pregonan una sociedad jerárquica y represiva, sometida a un poder sin freno, así como una economía dirigida por el Estado, todo para que Rusia sea una Potencia (derzhava) tan grande como lo fue la URSS.

Es precisamente por el conducto de la 'grandeza imperial' que se estableció la comunicación permanente, en ambos sentidos, entre los (neo) comunistas y los (neo) nazis. Veamos la lista alfabética de los movimientos mismos, a falta de tener un criterio más científico: ${ }^{12}$

${ }^{10}$ Retoma el nombre del periódico nazi de Julius Streicher Der Stürmer. De Limonov se puede decir que es el Mishima ruso.

${ }^{11}$ V. Korchaguin, Sud nad akademikom Korchaguinim, 1997, Moscú. Condenado por haber publicado textos antisemitas, fue amnistiado en seguida en 1995 con motivo del 50 aniversario de la victoria. Cuenta su proceso como una epopeya.

${ }^{12}$ Hay casi 100 organizaciones 'nacional-patrióticas', pero muchas son sólo un nombre para el investigador. Se estima que tienen 500,000 simpati- 
JEAN MEYER

- Centuria Negra, de Alexander Shtilmark (derecha antisemita).

- Derzhava, Fundada por Stanislav Terejov (se quiere de izquierda).

- Frente Nacional, fundado por Ilyá Lazarenko, actualmente dirigido por Konstantin Kasimovski. Lazarenko dirige Tserkov Navi.

- Frente Nacional Patriótico "Pamyat" (Memoria) de Dmitrii Vasiliev.

- Partido Nacional Bolchevique de Eduard Limonov (se quiere de izquierda)

- Partido Populista Nacional de Ivanov-Syjarevski.

- Partido Nacional republicano de Yuri Belyaev y Niko Lisenkó

- Partido Radical de Derecha, de Andrei Arjipov y Serguei Zharikov.

- R. N. E. (Russkoye Natsionalnoye Edinstvo) Unidad Nacional Rusa de Alexander Barkashov.

- Sociedad "Pamyat" (Memoria) de Valerii Emelyanov.

- Unión Nacional Rusa de Alexander Vdovin y (antes) K. Kasimovski.

16 - Unión de todo el Pueblo Ruso de Serguei Baburin (comunista). ${ }^{13}$

Sería ridículo contar al Partido Liberal Demócrata Ruso de Vladimir Zhirinovski entre esas organizaciones. Con todo y lo provocativo de la personalidad de su líder, dicho partido es cada día más populista (y menos popular) y poco o nada tiene de fascista. No es marginal como las otras organizaciones. Sin embargo, tres de ellas merecen un complemento de información: el Partido Nacional Republicano, el RNE y la Unión de todo el Pueblo Ruso. E1 PNR de Rusia fue fundado en 1990

zantes. Según el Laboratorio de Sociología de la MGU (Unidad Estatal de Moscú) $12.5 \%$ de los rusos entre 17 y 25 años son sensibles a su discurso (Moskovskië Novosti, 28 de junio, 1998, p. 6).

${ }^{13}$ Fichero del autor. Podría mencionar a muchas más como la Unión de Venedov de Viktor Bezverjci, Za russkoe delo de Oleg Gusev, etcétera. 
por Nikolai Lisenko; tiene su base en San Petersburgo y su doctrina consiste en que "el nacionalismo es la religión del siglo XXI". Este partido sigue siendo marginal y, aparentemente, menos extremista que el RNE. Por razones tácticas el PNR siguió un tiempo, en 1995-6, a Zhirinovski. En la Duma Lisenko se especializó en defender a los rusos de Crimea y en atacar a Ucrania, cuya bandera rasgó públicamente en el Congreso.

RNE (Unidad Nacional Rusa) nació en 1990 y tiene su origen en Pamyat. Pretende contar con 200,000 miembros, pero se le reconocen menos de 5,000. Sin embargo tiene 350 corresponsalías, de las cuales 100 han sido oficialmente registradas; esto quiere decir que dispone de la cuarta o de la tercera red nacional después del Partido Comunista y del partido liberal demócrata. El RNE se afirma nacionalsocialista; su líder, el golpista de octubre de 1993, Alexander Barkashov, proclama: "no soy fascista, soy nazi". El símbolo del RNE es una suástica combinada con una cruz, su lema: "una nación, un pueblo, un Estado". El grupo predica la pureza de la raza rusa, su revista se llama Orden Ruso (Russkii Poryadok), y gustan tanto de los uniformes negros como de los ejercicios paramilitares. El RNE rechaza toda participación electoral (a diferencia del PNRR). Incluso llegó a rechazar una alianza con Zhirinovski en 1995 "no porque es judío, sino porque es un 1oco" (Barkashov). ${ }^{14}$

La Unión de todo el Pueblo Ruso (ROS) de Serguei Baburin, comunista radical, nace a fines de 1991, en el momento del derrumbe de la URSS. Su lema es "una historia, una nación, una Rusia"; admite la vía electoral y pregona por la "unión de las fuerzas patrióticas", entre ellas incluye al partido comunista. Baburin fue el autor de la moción

${ }^{14}$ El Congreso Judío ruso (REL) publica una revista, Diagnoz Antifachistikoe Obozrenie. En el n 2 (invierno 1998) señala que verdaderos nazis son RNE, la Unión Nacional Rusa de Kasimovski y el Partido Populista Nacional de Ivanov. Ver Emmanuel Mendelevich "Chernoziomny fashizm" (fascismo de las tierras negras) en Russkaya Mysl, 4231, 16 de julio, 1998, p. 8. Y del ideólogo activista en Voronezh, Serguei Nechaev, La cuestión hebrea en Rusia a fines del siglo XIX y principios del XX, 1994, Voronezh. 
JEAN MEYER

que condenó al defensor de los derechos del hombre Serguei Kovalev, por su conducta en Chechenia. Dicha moción fue aceptada con 240 votos a favor y 75 en contra. En marzo de 1997 redactó otra moción proponiendo que el día 4 de octubre (aniversario del asalto a la Casa Blanca, sede del Congreso y del Soviet Supremo, ordenado por Yeltsin en 1993) fuese el Día de los Defensores de la Constitución.

Esas organizaciones han buscado militantes entre la población cosaca del Cáucaso, dentro del marco de la guerra de Chechenia. El atamán Yuri Churekov de la zona del Terek, al norte de Chechenia, declaró en una entrevista que había tenido contactos con el PC y con la ROS de Baburin, pero que el único que en verdad les prestaba atención era Barkashov (RNE). "Nos prometió la rehabilitación de la nación cosaca" y "poner en cintura a los montañeses balkardin, cherkess, ingush, chechen". Churekov, ideólogo de los cosacos del Terek, dice que el $80 \%$ de sus cosacos están a favor de RNE, y que los cosacos voluntarios lucharon junto con la milicia del RNE en la batalla de Grozny, en la 74 Brigada de voluntarios. ${ }^{15}$

Queda un último punto que se debe mencionar, pero que no se puede desarrollar por razones evidentes. Tanto la policía como el poder judicial han manifestado una paciencia y una indulgencia notables hacia esos grupúsculos, a su propaganda y a sus acciones violentas. Después de unos atentados contra sinagogas en Moscú y Riga, en mayo de 1998, el diputado Konstantin Borovoi no dudó en afirmar que sus autores pertenecían a esos grupos y que trabajaban con la anuencia de 'los servicios especiales'. Cuando se le preguntó al FSB (Servicio Federal de Seguridad) qué pensaba de esos atentados, contestó: "Todo bajo control; controlamos esas organizaciones." Según Borovoi eso significa que el FSB las manipula: "Las organizaciones

${ }^{15}$ Russkaya Mysl, 4164, 6 de marzo, 1997, p. 3. El 3 de octubre de 1998 se reunió en Moscú un Congreso para unificar 62 organizaciones (oficiales, cosacos, monarquistas, radicales de todo color). En el presidio estaban, entre otros, Baburín y Anpilov. Asistieron Limonov, el vicepresidente de Transnistría, el viceprimer ministro de Chechenia (i!). Ver Russkaya Mysl, 4240 del 8 de octubre, p. 2. 
fascistas no tienen un apoyo ni un financiamiento oficial, pero son un peligro real. Podrian ser financiadas por los servicios especiales. Ya ocurrió; lo vi hace tres años en Jimki y Mutishcha; se juntaban en una fábrica secreta de armamento vigilada por el FSB. No hubieran podido hacerlo $\sin$ la ayuda de los servicios especiales." ${ }^{\text {"16 }}$ Vieja historia soviética y rusa, vieja historia universal.

\section{Ideas, pasiones-ideología}

a) Iremos de lo particular a lo general

La revista Bolshebnaya Gora (La Montaña Mágica) reunió a un grupo interesante: Alexander Duguin; el escritor franco-ruso Eduard Limonov, quien intentó un tiempo ser el ideólogo de Zhirinovski antes de romper con él; Gueidar Dzemal, Mamleyev. Esa colección heteróclita de fuertes individualidades no duró y cada quien se fue por su lado, ¿qué tenían en común? Cierto tradicionalismo esotérico, algo de aristocratismo al estilo Julius Evola, una referencia consciente a la 'revolución conservadora, ${ }^{17}$ (al hitlerismo lo critican por ser 'plebeyo', 'de masa', no por otra cosa), una predilección por la 'geopolítica', 'los juegos estratégi$\cos ^{\prime},{ }^{18}$ todo esto culminaba en un heroísmo escatológico que lleva a la victoria o al 'crepúsculo de los dioses'. No son hombres de iglesia, pero la religión les interesa como 'fuerza'. No son cristianos, ni musulmanes, son ateos, nietzscheanos, a veces se proclaman 'paganos'.19

${ }^{16}$ Russkaya Mysl, 4226, 11 de junio, 1998, p. 8. En Izvestia, el 7 de junio de 1998, Alexander Yakovlev dijo: "La KGB sembró el fascismo ruso". El político con experiencia sabe de qué habla.

${ }^{17}$ Ver Ernst Nolte, La guerra civil europea, 1994, México, FCE; y también de Thomas Molnar, La contre revolution, 1972, París.

${ }^{18} \mathrm{El}$ autor más citado es Karl Haushofer, ver su De la géopolitique, 1986, París, Fayard, traducido del alemán por André Meyer.

${ }^{19}$ Alexander Agadjanian, "Les cultes orientaux et la nouvelle religiosité en Russie", Revue d'Etudes Comparatives Est-Ouest, 1993, 3-4, p. 155-71:. 
JEAN MEYER

La Iglesia ortodoxa rusa (IOR) les interesa como 'tradición sacral' y un Dzemal no cree que exista un antagonismo esencial entre el cristianismo y el Islam. Piensan que esos dos monoteismos históricamente rusos pueden unirse en su panteismo. Reconocen en el bolchevismo una idea 'titánica', que consideran 'equivocada', pero que supo entender que a Rusia le tocaba el papel más importante en el 'proyecto histórico mundial". Comparten una visión mítica del mundo y de la historia como lucha entre dos principios, el orden y el caos. El 'proyecto histórico global', siendo heroico, necesita grandes y terribles fuerzas irracionales que sólo el sincretismo religioso puede engendrar: requiere del sacrificio. Alguna vez Umberto Eco definió al fascismo "no (como) la lucha por la vida, sino (como) la vida por la lucha".

\section{b) Alexander Duguin ${ }^{20}$}

Merece atención por la clara articulación de sus tesis. Nació en 1962, años después entró como estudiante al Instituto de Aviación de Moscú, del cual pronto fue excluido; posteriormente, en 1991, empezó a escribir en el diario Dien, sobre las sociedades secretas, el ocultismo, la guerra secreta. Poco después entró a la redacción y fundó Arktogueya $A C$, club cultural y editorial especializado en esoterismo y tradiciones. En 1993, con Eduard Limonov, creó el partido nacional-bolchevique. En 1995 fue candidato infeliz al Congreso. Ha publicado ocho libros. En uno de ellos, Konspirologuia, interpreta la historia mundial como la lucha eterna entre el Mar Océano (Atlántico) y la Tierra Eurasia, la 'talasocracia' (Morya) contra la 'telurocracia' (Sushi). Su centro de reflexión 'meta-estratégico' Eon tiene contactos con las

${ }^{20}$ Alexander Duguin, Osnovy Geopolitiki; Konspirologuiya; Geopoliticheskoe Budushchee Rossii, 1997, Moscú. Entrevistado por Alexander Yanov (Alexander Duguin ot imeni Evrazii), Moskovskie Novosti, $\mathrm{n}^{\circ} 7,23 \mathrm{de}$ febrero, 1998. 
¿EXTREMA DERECHA EN RUSIA?

Fuerzas Armadas: realiza análisis geopolíticos sobre las relaciones que sostiene Rusia con Europa y los Estados Unidos. ${ }^{21}$

Duguin sueña con la 'revolución'. La guerra civil es un 'mal menor' comparado con 'el compromiso que destruye Rusia'. Rusia debe seguir el ejemplo serbio, 'ir en peregrinación a Serbia' para deshacerse de un gobierno compuesto de 'criminales nacionales con los cuales ningún acuerdo es posible'. Yanov apunta que muchas frases suyas podrían llevar la firma de Lenin, hombre que en 1905 era un marginal poco conocido; se trata del mismo radicalismo, del mismo maniqueísmo, y del mismo odio contra toda forma de compromiso. Más una fuerte dosis de geoestratégia alemana (Ratzel y Haushoffer con la obsesión del espacio): "Si no integramos todo el espacio post-soviético para tomar control del corazón geopolítico del mundo, lo que nos espera es un futuro colonial." 22

Yanov dice que Duguin es "quizá el único pensador serio de la oposición" que va hasta el fin de su pensamiento (como Lenin) sin miedo, expresando en voz alta lo que muchos piensan. Ha elaborado una nueva concepción del futurismo eslavófilo del siglo pasado: ${ }^{23}{ }^{\prime \prime} \mathrm{El}$ imperio de Eurasia será el centro del antimundialismo, de la antiglobalización, para liberar al mundo del 'dominio bancocrático americano'."' No duda en decir que la URSS, por razones de determinismo geopolítico, era la heredera del III Reich. Para él, ya basta de resistencia pasiva, hay que atacar agresivamente: "sólo el Islam fatalista y antiindividualista se encuentra tipológicamente próximo a la ortodoxia rúsa (...) contra la seudocristiandad anglo-sajona individualista y pro-

21 Alexander Yanov, "Ob ideiax y knigax Aleksandra Duguina", Moskovskie Novosti, $\mathrm{n}^{\circ} 3,25$ de enero, 1998/10'11. Duguin, en la línea del 'tradicionalismo esotérico', publica en ruso a René Guénon y a Julius Evola. Escribió también La Revolución conservadora, Templarios del proletariado: nacional-bolchevismo e iniciación, y bajo seudónimo Metafisica del terror. Ver su manifiesto en el $\mathrm{n}^{\circ} 8$ de Elementi: "Nacional-bolchevismo o nada".

${ }^{22}$ Yanov, op. cit., 25 de enero, 1998, p. 10.

${ }^{23}$ Ver por ejemplo a Nikolai Y. Danilevski, La Russie et l'Europe, 1871, París. Hitler hubiera podido firmar muchas de estas páginas. 
JEAN MEYER

testante". Afirma que hay que escoger entre el "patriotismo místico y el terrorismo criminal (del Estado actual)". "Yeltsin es Kerenski... Stalin sigue después. Ya viene en camino, es imposible que no llegue." Cita a Karl Schmitt ${ }^{24}$ para explicar que "debemos llevar una guerra de partisanos (guerrilleros) contra la nueva Cartago (...) la pequeña guerra de partisanos ya empezó en los Balcanes, en Libia, en Irak contra el Nuevo Orden Mundial". "Nuestro partisano estará armado de cabezas nucleares y de cohetes", "Rusia puede parar la dictadura mundialista." "El gran pueblo ruso debe ir a esa guerra en nombre de su destino sangriento, eslavo y cristiano." Duguin desarrolla una retórica de guerra, sangre y muerte heroica: guerra a muerte contra la rusofobia hasta la última gota de sangre, "no hay más vía que la de la Revolución Absoluta (...) contra el mundo contemporáneo como mundo del Anticristo". Ese misticismo de la muerte y de Rusia ("la Rusia celeste, la Nueva Jerusalén') no tiene nada en común con el pensamiento leninista y remite a la noción muy aplaudida del 'excepcionalismo ruso'.

¿Quién lee a Duguin? Está en contacto con la extrema derecha europea, ligado por ejemplo al belga Jean Thiriart y al francés Alain de Benoit $^{25}$ quien, por su conducto, presentó unas conferencias en la 22 Academia del Estado Mayor General en Moscú. Efectivamente, "si bien los libros de Duguin no son libros de texto (en la Escuela de Guerra), aun así nos interesan", dice el general Nikolai Pavlovich Klokotov, profesor de estrategia en la Academia del Estado Mayor General. $^{26}$

${ }^{24}$ Karl Schmitt, Teoría del partisano, 1985, México.

${ }^{25}$ A. de Benoit y el GRECE (Grupo de Investigaciones y Estudios para la Civilización Europea) en contacto con todas las extremas derechas europeas.

${ }^{26}$ Alexander Yanov, in Moskovskie Novosti, op. cit., 25 de enero, 1998: II. Duguin acaba de romper con Limonov. Ver entrevista con Limonov en Moskovskie Novosti, 28 de junio, 1998, p. 6, y V. Lijachev y V. Pribylovskii, "Cisma entre los nacional-bolcheviques", en Russkaya Mysl, 2 de julio, 1998, p. 9. Limonka, en sus números 91 y 92 de mayo de 1998, denuncia al traidor Duguin, quien contrataca en el $\mathrm{n}^{\circ} 0$ de Vtorzhenie, editado por el diario Zavtra. 
¿EXTREMA DERECHA EN RUSIA?

c) "Cosmismo" y "Eurasianismo"

Los nacionalistas extremos siguen el ejemplo nazi y prefieren el paganismo al cristianismo 'propio de otras razas', y siguen la fórmula: '¡volvamos a nuestros dioses!'. 'Una fórmula mitigada del neopaganismo romántico-nacionalista que, al menos superficialmente, parecería compatible con el cristianismo ruso-ortodoxo es el llamado 'cosmismo' ruso, que por supuesto sólo puede hallar éxito entre los intelectuales visionarios de ideas más bien esotéricas o por lo menos intelectuales a medias. A veces ese cosmismo se combina con fantasías historiosóficas coloreadas de gnosticismo, como en el fallecido Lev Gumilëv."27

En 1920 el ideólogo del nacional-bolchevismo Nicolai Ustrialov escribía que "por la lógica misma de las cosas el jacobinismo bolchevique tenía que evolucionar hacia un napoleonismo. (...) El bolchevismo, con la influencia internacional que ganó y sus relaciones que penetran por todos lados, se vuelve para Rusia un maravilloso instrumento de política internacional. ¡Cuán ciegos los patriotas rusos que quisieran a toda costa quitar al país dicho instrumento! (...) Sólo un Estado 'fisicamente' poderoso puede poseer una gran cultura". ${ }^{28}$

Casi al mismo tiempo que Ustrialov surgió la corriente de 'Eurasia' entre los rusos que habían emigrado a Sofia, Praga, Berlín, Shanghai y París. En los años 30 París fue la sede de las 'ediciones eurasianas', las cuales contaban con la presencia de lingüistas, historiadores y etnólogos como Georgui Vernadski, Nikolai Trubetskoi, Pietr Savitski.

${ }^{27}$ Lev Gumilëv, ingeniero, diletante muy dotado, hijo del poeta Nikolai Gumilëv, que fue fusilado en 1921 y de la poetisa Anna Ajmatova. Autor prolífico, muy leído. Entre muchos otros títulos: Etnogénesis y biosfera de la tierra, 1990, Leningrad. Se presta a todas las lecturas racistas. La cita es de Serguei Averinzev, "Corrientes actuales del espíritu en Rusia", Vuelta, $\mathrm{n}^{\circ} 244$, marzo de 1997, p. 13 (traducido del alemán).

${ }^{28}$ Citado por Michel Heller, Soixante dix ans qui ébranlèrent le monde, 1988, París, Calmann Lévy, p. 250. Mijail Agursky, The Third Rome: National Bolshevism in the USSR, 1987, Boulder. 


\section{JEAN MEYER}

Estamos hablando de pensadores de alto nivel que, desconcertados por la revolución bolchevique, intentaron entenderla e interpretar su sentido en la historia de Rusia y del mundo. Encontraron una clave en el 'determinismo geopolítico', y retomaron del eslavofilismo la desconfianza hacia 'el Occidente', pero rechazaron la alternativa Este/ Oeste, y propusieron la sintesis: Rusia no es Europa, Rusia no es Asia, Rusia es Eurasia. Los anticomunistas, como Ustrialov, admiraron el gran poder del Estado soviético y su patriotismo los empujó a aceptarlo. No eran 'reaccionarios', eran 'patriotas'. Pensaban que Rusia debía dotarse de un Estado 'religioso', con una 'ideocracia' que sometería toda la vida a la idea dominante. Soñaban con resucitar el antiguo imperio de Gengis Khan, el imperio de las estepas y de los Escitas. $^{29}$

El discurso eurasiano perdura: Nikita Mijalkov, el famoso cineasta recién nombrado (1998) presidente de la Unión de los Cineastas Rusos, escribía en 1991 al Primer Ministro Ivan Silaïev: "Los rusos no son europeos ni asiáticos. Tuvimos en el pasado nuestra vía propia y la tendremos en el porvenir. Es la vía eurasiana." 30

\section{d) El antisemitismo}

La extrema derecha no pertenece al nacionalismo común; es un nacionalismo delirante en su extremismo y moralmente fuera de la norma. Necesita de un adversario, necesita de un chivo expiatorio, y lo encuentra. La explosión de actividades esotéricas después de la caída del comunismo (antes se trataba de 'sectas secretas') ${ }^{31}$ se combinó

${ }^{29}$ Walter Laqueur, Fin de siècle, 1997, New Brunswick, p. 66-7. Georges Nivat, Vers la fin du mythe russe, 1995, París, p. 137-8. Ver también P. Sériot-N. S. Troubetzkoy, L'Europe et l'humanité, 1996, Liége.

${ }^{30}$ Nivat, op. cit., p. 137.

${ }^{31}$ Los rusos consumen con entusiasmo la literatura al estilo New Age. Por cierto, hay que recordar que a principios del siglo su primer profeta fue el 'mago' ruso Gurdjief. Blavatsky y Ouspensky también son rusos. 
con la creencia en conspiraciones 'satánicas": "los demócratas son demonios, mataron a Cristo y ahora quieren matar a Rusia", dijo el metropolita de Leningrado Ioan de Ladoga. ${ }^{32}$ El viejo prelado creía que todos los demócratas eran judíos, que los judíos eran un pueblo culpable de deicidio y que los Protocolos de los Sabios de Sión, apócrifo creado por la policía zarista, eran tan ciertos como los evangelios.

Al citar los Protocolos nos remitimos al pasado: a las Centurias negras, a la Unión panrusa, a los pogroms de los últimos años del zarismo. El antisemitismo virulento que caracteriza a los Protocolos, más violento que cualquier otro en la Europa de esas fechas, fue recalentado entre ciertos grupos de emigrados después de la revolución, cultivado en la URSS en tiempos de Stalin y de nuevo después de Jrushchov. Este antisemitismo fue una de las cien flores que crecieron sobre el estiércol de la destalinización y del 'estancamiento'. Es difícil distinguir entre el antisemitismo popular y su creación-manipulación por parte del Estado. Ahora sabemos que el movimiento Pamyat (Memoria), fundado a principios del los años 80 , fue lanzado por la $\mathrm{KGB}$, quizá por el general Sterligov. Este movimiento de acción cultural teóricamente dedicado a la salvación del patrimonio arquitectónico pudo desarrollar sin problemas un antisemitismo fanático, sólo castigado cuando se volvía demasiado anticomunista. ${ }^{33}$

Pero Pamyat pronto levantó vuelo y engendró un sinfín de grupúsculos que compartían el mismo miedo a las 'fuerzas satánicas' que trabajaban en la perestroika y luego bajo 'el régimen de ocupación' de Yeltsin. Para ellos la perestroika y luego la república de Rusia son el resultado de un 'complot sionista de Wall Street'; y consideran que el pueblo ruso se encuentra como un 'extranjero en su propia casa', 'amenazado de extinción biológica y cultural'. Esa 'idea' de un complot mundial bajo el dominio judío (masones, católicos, jesuitas, demócratas, capitalistas, el papa... todos son judíos, como Marx, Zinoviev,

${ }^{32}$ Muerto en 1995.

${ }^{33}$ Para Pamyat, Walter Laqueur, en Fin de Siècle, op. cit., p. 156-7, cita a Mijail Leontiev en Atmoda (Riga Weekly). 
JEAN MEYER

Kamenev, Trotski; sólo Stalin no lo era) se vuelve a encontrar bajo la pluma de un matemático respetable, el valiente antiguo disidente, Igor Shafarevich, autor del famoso libro Rusofobia.

En 1995 el ex-general de la KGB Sterligov anunció que una organización secreta judía controlaba el gobierno. Mientras tanto Zhirinovski se alegraba con la idea de mandar algún día a Yegor Gaidar a un campo de concentración en un vagón de ferrocarril para el ganado. Asimismo, Vedenkin prometía que él personalmente mataría a Serguei Kovalev y a S. Yushenkov... ${ }^{34}$ En 1996, 1997 y 1998 la misma prensa denuncia: ¿Boris Nemtsov? ¡judío!, ¿Grigori Yavlinski? ¡judío!, ¿El pelirrojo Tolia? ¡judío!, ¿los banqueros Guzinski, Berezovski? ¡judíos!

En lugar de pronunciar el nombre del presidente Yeltsin, dicen 'Eltsin' para señalar que no se trata de un nombre ruso, sino de un nombre judío. ${ }^{35}$

En fin, no inventan nada; manejan el mismo 'tilichero' ideológicopasional que sus colegas europeos. En este sentido son muy europeos, occidentales. Como el 'nazismo' en Rusia es fundamentalmente postcomunista, no hay que sorprenderse de la ausencia de la dimensión tradicionalmente anticomunista de ese tipo de movimientos. No sólo

26 no es anticomunista, sino que es un factor en la simbiosis, en la mutación que afecta al antiguo comunismo ruso, el cual se transforma de internacional-socialista, o de soviético, a nacional-bolchevique, nacional-patriótico, nacional-popular, por no decir nacional-socialista. Por eso los comunistas rusos han llegado al extremo de defender al diputado y ex-general Albert Makashov, antisemita reincidente, y a hacer suya la tesis de la participación de los judíos en un complot internacional contra Rusia. El 7 de octubre de 1998, Makashov afirmó en un mitin convocado por el PC: “iTodos los judíos a la tumba!’ Luego, el

${ }^{34}$ Moscow Times, 2 de abril, 1995.

${ }^{35}$ Nemtsov, gobernador de Nizhni Novgorod, 1lamado a altas responsabilidades en el gobierno federal; Yavlinski, dirigente del partido demócrata de oposición Yavloko; Tolia (Anatoli Chubais), el hombre de las privatizaciones, el artesano de la victoria electoral de Yeltsin en junio de 1996, etcétera. 
¿EXTREMA DERECHA EN RUSIA?

7 de noviembre en la plaza roja durante la conmemoración del $81^{\circ}$ aniversario de la revolución bolchevique, fue muy aplaudido por los manifestantes. Cuando en la Duma se presentó una declaración desaprobando a Makashov, el PC y el partido de Zhirinovski votaron en contra. Zyuganov dijo que su partido estaba a favor de "la amistad y de la fraternidad entre los pueblos", pero que "los judíos en el gobierno y los medios se habían aliado con extranjeros en una campaña para debilitar el nacionalismo ruso y agotar la fortaleza de la nación". ${ }^{36}$

\section{Contaminación: comunistas y ortodoxos}

\section{a) Los comunistas}

Si bien el PC sigue siendo el primer partido de Rusia, a su lado existen varios pequeños partidos comunistas disidentes y también grupúsculos radicales. Desde un principio se multiplicaron los contactos entre ultra-nacionalistas y comunistas a través de la derzhava, de la nostalgia del Gran poder y de la grandeza imperial. Así se retomó la vereda poco transitada, pero ya antigua, del nacional-bolchevismo, abierta en 1919-1920 por Karl Radek, Strasser y Ustrialov. ${ }^{37}$

Los que dudaron por un tiempo fueron los derechistas, pero el nacionalismo exaltado del 'coronel negro' Viktor Alksnis, de Viktor Anpilov y del general Makashov, los tranquilizó después de la batalla por la Casa Blanca ${ }^{38}$ Desde octubre de 1992 el Partido Comunista era representado por su secretario general Guennadi Zyuganov en el Frente de Salvación Nacional. En cuanto a Viktor Anpilov, el comunista radical, con un brillante pasado de internacionalista en Cuba y Nicaragua,

${ }^{36}$ Moskovskie Novosti, 11-18 de octubre, 1998; Russkaya Mysl, n 4241, del 15-21 de octubre, 1998, p. 10.y Michael Wines, New York Times, 9 de noviembre de 1998.

${ }^{37}$ Ernst Nolte, La guerra civil europea, 1994, México, FCE.

${ }^{38}$ Jean Meyer, La extraña batalla de Moscú, 1995, CIDE, División de Estudios Internacionales, documento de trabajo, $\mathrm{n}^{\circ} 18$. 
JEAN MEYER

se encontraba compitiendo con Barkashov por el primer lugar entre los extremistas. ${ }^{39}$ Anpilov, líder de Trudovaya Rossia (Rusia Trabajadora), fue encarcelado después de la batalla de la Casa Blanca, en octubre de 1993. Poco tiempo después fue rápidamente amnistiado, como todos, y volvió a la lucha con más ganas; pronosticando la guerra civil a gran escala, dijo que "el combate seguirá hasta la victoria en cuanto sea el combate de la patria y del pueblo entero (...) quizá este año, quizá durará años y costará grandes tormentos". 40

Dentro de esa línea nacional-bolchevique se encuentra hoy en día el gobernador de Krasnodar, en el sur de Rusia, el comunista sin partido Nikolai Kondratenko, experto en xenofobia y antisemitismo. ${ }^{41}$

Guennadi Zyuganov, el secretario general del PC y candidato a la presidencia de Rusia, ha sufrido una evolución notable, exaltando la continuidad histórica entre Rusia y la URSS, asimilando tantas nociones de la derecha que uno ya no sabe dónde situarlo. Como Duguin, despotrica contra la 'nueva Cartago', los Estados Unidos. También como Duguin, tiene una predilección por los juegos geopolíticos; $\mathrm{y}$ tiene por meta devolver a Rusia su estatuto de gran potencia, pero - y la diferencia es muy importante- descarta la guerra mundial como medio para lograrlo. Zyuganov es un autor muy prolífico y bastante repetitivo. La lectura de su Rusia, patria mía. Ideología del patriotismo de Estado y de su Creo en Rusia es suficiente. ${ }^{42}$ Este antiguo profesor de historia se ha metido a fondo en la lectura de los eslavófilos del siglo pasado y

${ }^{39}$ Viktor Anpilov y los nacional-bolcheviques, en Moskovskie Novosti, 28, 10 de julio de 1994, p. 11; idem, $\mathrm{n}^{\circ} 20,15$ de mayo, 1994.

${ }^{40}$ Mokovskie Novosti, $\mathrm{n}^{\circ} 20,15$ de mayo, 1994, p. 2. El $1^{\circ}$ de octubre de 1998 se reunió en Moscú el primer congreso pan-ruso del Partido Nacional Bolchevique. Estuvieron presentes, al lado de E. Limonov, Stanislas Terejov y Viktor Anpilov (Russkaya Mysl, 4240, 8 de octubre, 1998, p. 2).

${ }^{41}$ Russkaya Mysl, 4209, 12 de febrero de 1998, p. 5. Ver también de Viktor Zolotarevich, "Politicheskaya tsvetoslepota", en el mismo número, sobre la unión de rojos y pardos, y sobre el nuevo movimiento radical-nacionalista Zolotoi Lev.

${ }^{42}$ Ambos libros fueron publicados en Moscú en 1996 por Informpechat. 
¿EXTREMA DERECHA EN RUSIA?

de los eurasianos del presente. Nikolai Gumilëv es uno de sus autores más citados. Como explica orgullosamente en su Rusia, patria mía: "Mil años de nuestra historia han demostrado que somos un pueblo de idealistas, un pueblo de soñadores, un pueblo de vencedores."

Bajo la invocación de Haushoffer (el espacio, la geopolítica), de Stalin y de Gumilëv, Zyuganov cree que "por primera vez en tres siglos tenemos una posibilidad real de construir la unidad sinfónica 43 de nuestras tradiciones espirituales y estatales" (p.148). Stalin estuvo a punto de lograrlo $y$, de haber vivido cinco o seis años más, hubiera llevado a cabo su 'perestroika ideológica' en esa tradición sinfónica (p.141-3). Zyuganov también afirma su convicción de que existen las "perspectivas de una humanidad estable y desarrollada" con base en "los valores fundamentales del estalinismo de la post-guerra, o. sea la ideología del patriotismo rusista" (misist).

"La ortodoxia es la fuente de la comunidad (sobornost) rusa, de su patriotismo, de su potencia. Una de las muchas virtudes del comunismo ruso para millones de ciudadanos de la URSS es que era una variante de la fe cristiana en un porvenir luminoso para todos los justos. Vivir según la ley, amar a su prójimo, llenar otras obligaciones, son valores compartidos por el cristianismo y el comunismo" (278-9). Zyuganov evoca sus encuentros con obispos y sacerdotes ortodoxos antes de la segunda vuelta de las elecciones presidenciales de 1996 y recuerda con gusto cómo el patriarca Alexei II condenó a las "religiones extranjeras" y cómo la ortodoxia fortalece los lazos "entre patriotas y comunistas de Rusia". (p. 277-8).

En su libro Creo en Rusia cita a Gumilëv desde la primera página y lo vuelve a citar sin descanso, especialmente en su capítulo "La antigua Rusia y la gran estepa", cuando retoma la idea de su gurú según la cual "los mongoles salvaron a la iglesia ortodoxa rusa de los católicos". Más eurasiano no podría ser. Para él, Lev. N. Gumilëv es "uno

${ }^{43} \mathrm{La}$ sinfonía es un viejo concepto teológico-político que se remonta a Bizancio y que fue retomado por el zarismo y la iglesia ortodoxa. Las citas que siguen han sido tomadas de Rusia, patria mía, 1996. 
JEAN MEYER

de los pensadores sistemáticos más importantes del siglo XX" y "su filosofia de la historia es, en el mundo actual, tan importante como la de Marx en el siglo pasado" (p. 37). Para un ruso, Gumilëv es más importante aún porque Marx tenía una desconfianza total hacia los rusos, mientras que Gumilëv exaltaba su vocación histórica. Para terminar con Zyuganov hay que leer esta frase: "El plan (del enemigo) es el siguiente: por el camino de la orientación de la población hacia el espíritu 'democrático', captar una sociedad desorientada que ha perdido su inmunidad real, la que está ligada a un sano conservadurismo intuitivo y el instinto de autodefensa." ${ }^{44}$ En el mismo texto Zyuganov cita con encomio a Karl Haushoffer.

\section{b) Los ortodoxos}

El 21 de enero de 1997, aniversario de la muerte de Lenin, en una reunión dentro de la Academia del Ministerio del Interior (Gobernación) se debatía 'sobre la nueva idea nacional para Rusia'. Abundaban las sotanas negras de sacerdotes ortodoxos y los uniformes azules de los futuros policías. El cineasta Nikita Mijalkov, autor de Quemados por el sol, se preguntó en un discurso porqué no volverían los rusos a la idea nacional de la Rusia zarista: "ortodoxia, autocracia y genio del pueblo", sin renegar de la grandeza soviética. ${ }^{45}$

"En ningún caso puede existir una nueva idea nacional fuera de la ortodoxia, que debe volver a ser asignatura obligatoria en las escuelas", prosiguió Mijalkov. El jefe del movimiento Ortodoxia rusa, Alexander Burkin, propuso instaurar en los pueblos nuevas 'troikas' (comisiones encargadas de aplicar el terror bolchevique) compuestas por un jefe de la administración local, un jefe de policía y un sacerdote, para lograr que "el hombre de la calle regrese a los verdaderos valores", Mijalkov

${ }^{44}$ Zyuganov, Al cruce de caminos. Metodología y fuentes, 1996, Moscú, p. 35; citado por Valeri Senderov, "El socialismo mágico", en Russkaya Mysl, 4158, 23 de enero de 1997.

${ }^{45}$ Moscú, AFP, 21 de enero de 1997. 
retomó la palabra para decir que "la ortodoxia debe saber defenderse y discernir a los que quieren el bien de la patria de los que quieren tan sólo llegar al poder". Zhirinovski no se dio por aludido y gritó: "no tenemos tiempo para construir miles de iglesias y formar una nueva generación de sacerdotes (...) pero podemos ayudaros (a los clérigos) a bloquear leyes en el parlamento, a enmendar otras". "Rusia perdió su idea nacional y podemos tomar como base la idea de la ortodoxia", estimó Dmitri Filipov, -alumno policía de 19 años. "Si recobramos nuestra espiritualidad, el número de crímenes podría disminuir", dijo su compañero Andrei Yazov de 18 años. ${ }^{46}$

Alexei Podberiozkin, diputado a la Duma, miembro de la Unión Popular Patriótica coordinada por el comunista Zyuganov, y presidente de la asociación Patrimonio Cultural, sintetiza la nueva simbiosis entre comunistas, nacionalistas y ortodoxos: "Veo seis factores principales para el regreso de la ortodoxia. La Iglesia fue siempre un actor espiritual que supo fortalecer al Estado, tanto bajo los zares como hoy. La Iglesia levantó siempre muy en alto el patriotismo de la nación rusa. Ella se encuentra en el origen de nuestra lengua, de nuestro alfabeto y de nuestro arte; y ejerció una acción educativa mayúscula cuando la monarquía descuidaba ese aspecto. Finalmente, el calendario litúrgico ritma nuestra vida cotidiana y los edificios religiosos nuestro paisaje. La Iglesia Ortodoxa Rusa (IOR) no es una religión entre las demás, es fundadora de nuestra cultura." 47 Vladimir Bondarenko, amigo del líder francés del Frente Nacional, Jean Marie le Pen, y secretario de la Unión de Escritores, no habla de otra manera: "la ortodoxia, como lo dice su nombre, representa al cristianismo de los orígenes. Si desaparece Rusia, el cristianismo desaparece, es el Apocalipsis". ${ }^{48}$

La prensa radical, tante de izquierda como de derecha, publica artículos de sacerdotes y obispos especialmente duros. Mientras tanto el

${ }^{46}$ Moscú, AFP, 21 de enero de 1997.

${ }^{47}$ Christian Marakian y Sophie Lambroschini, "Russie, l'Eglise dans le piège nationaliste", Le Point, 11 de enero, 1997, p. 48.

${ }^{48}$ Idem. 


\section{JEAN MEYER}

nacional-bolchevismo encuentra eco entre la jerarquía. Por esto no debe extrañarnos que el metropolito Kiril de Smolensk, un tiempo considerado como moderado, no dude en comparar la ampliación de la OTAN hacia el Este con la 'venida del Anticristo'. ${ }^{49}$ En 1997 la batalla por la nueva Ley sobre la Libertad de Conciencia y las Organizaciones Religiosas ${ }^{50}$ puso muy en claro el discurso común nacionalcomuno-ortodoxo y la existencia de alianzas entre dichas fuerzas. El año anterior el ultra derechista P. Alexander Shargunov, uno de los líderes del extremismo sacerdotal, había apoyado la campaña electoral de Zyuganov contra Yeltsin. Asimismo, el periódico Zavtra presumió de haber convencido a Zyuganov de apuntar en su plataforma electoral a la ortodoxia como levadura de la nación rusa. Izquierda y derecha se unen en la ortodoxia considerada como fuerza ideológica. ${ }^{51}$

No todos los sacerdotes, obispos, y ortodoxos son fundamentalistas, pero la mayoría se inclina hacia la derecha. Lo que no es fácil medir es la influencia real de la IOR sobre la sociedad rusa; una hipótesis que hago mía es que generalmente se sobrestima esa influencia, ${ }^{52}$ se exagera la importancia de la religión. Ahora bien, el problema es que a

${ }^{49}$ Jean Meyer, "Russie: la loi sur la liberté de conscience", Esprit, Octubre, 1998, p. 99-109.

${ }^{50}$ Jean Meyer, "Orthodoxy and Politics in today Russia", ponencia en el IV Congreso Internacional Church State Relationship in Central and Eastern Europe, Cracovia, 12 de diciembre, 1998. Ortodoxia e identidad nacional en Rusia, Foro Internacional, XXXVI-3, p. 498-511.

${ }^{51} \mathrm{P}$. Shargunov, antiguo disidente, se ha vuelto todo un integrista. En 1993 fundó con otros sacerdotes el Comité para el Renacimiento Moral de la Patria, contando con el apoyo de Valentin Rasputin, Vasilii Bielov e Igor Shafarevich. Publicó un panfleto muy violento contra los liberales, los ortodoxos progresistas, los católicos y el ecumenismo: El Anticristo en Moscú. Maneja la invectiva y el anatema con mucha facilidad. Sovietskaya Rossia publicó su manifiesto el 23 de enero de 1997.

${ }^{52}$ En el Congreso Internacional de Cracovia, en diciembre de 1997, los investigadores rusos Alexander Agadjanian, Dimytr Furman, Elena Kalinichenko presentaron encuestas y sondeos en ese sentido. 
estas alturas no se trata de religión, sino de ideología. Por lo mismo debemos hablar de ortodoxismo y no de ortodoxia, por razones científicas y también para no hacerles el juego a los que ganan con la confusión. El fundador de la derechista Action Française, Charles Maurras, movilizó a muchos católicos, pero su catolicismo era muy especial: admiraba a la institución dos veces milenaria y no quería para nada al nazareno Jesús. Su línea política frente a la religión corresponde a la del ortodoxismo. ${ }^{53}$ Como en su práctica histórica la ortodoxia eslava, griega, balcánica, caucásica no ha conocido aún la laicidad fundada sobre la separación de la Iglesia y del Estado, cae muy fácilmente en ortodoxismo; como los católicos en el siglo XIX cuando no concebían la libertad religiosa, la tolerancia, el pluralismo. Por lo mismo, el mundo ortodoxo sigue siendo, en su mayoría, mentalmente ajeno a la idea de cambio, de evolución y considera el cambio como una traición. Esto es lo que fascina a los nacional-bolcheviques.

\section{Conclusiones}

Toda Rusia se fue a la derecha en los últimos diez años. En ese marco tres componentes arman un triángulo de fuerzas:

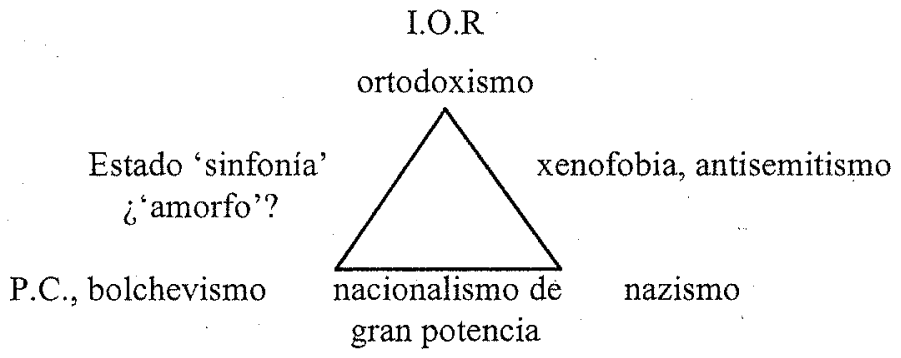

Bajo estas condiciones, ideas, pasiones y personas circulan por las tres caras del triángulo, lo que hace de la contaminación una regla. La amenaza para una república rusa democrática, todavía en porvenir, no

${ }^{53}$ Francois Thual, Géopolitiyues de l'orthodoxie, 1994, París, Dunod. 
JEAN MEYER

viene tanto de una extrema derecha grupuscular, sino de la confusión manifestada por palabras compuestas: pardirrojo, rojinegro, nacionalbolchevique, nacional-popular, nacional-patriota. Los nacionalistas de extrema derecha no parecen capaces de ofrecer una alternativa política pero, utilizados al principio por los neocomunistas que creían manipularlos fácilmente, han transformado a aquéllos en nacional-socialistas. Si es cierto que en Francia una parte del electorado comunista ha caído en la tentación de votar por el ultraderechista Frente Nacional de Jean Marie Le Pen, el PC francés no ha sido contaminado por las tesis de aquél. En los otros países europeos, incluso en las ex 'democracias populares', los partidos comunistas, rebautizados o no, siguen siendo 'de izquierda'. Esto se debe a que no han sufrido, no sufren una crisis comparable a la que viven los rusos.

Esa diferencia, que corresponde en el caso de Polonia, Chequía y Hungría a una experiencia política democrática anterior al comunismo, nos lleva a reconocer la inadaptación de nuestro vocabulario político (derecha/izquierda) al caso ruso. Por eso a la pregunta: ‘ ¿Se puede hablar de extrema derecha en Rusia', se prefiere contestar: 'no, sino de un nacionalismo extremo que puede atraer a gente muy diversa'.

$\mathrm{Ni}$ el partido comunista, ni el partido liberal demócrata son hoy revolucionarios. Juegan el juego electoral e institucional, pero también sufren de la misma tendencia a la contaminación, formando contra el presidente Yeltsin y su gobierno un 'bloque patriótico'. En 1993, el descontento popular aprovechó las elecciones legislativas para manifestarse a favor de Zhirinovski y de su PLD, y en 1995 a favor de Zyuganov y de su PC; pero en las elecciones presidenciales de 1996 se manifestó en favor del general Lebed, antes de votar 'con la razón' en la segunda vuelta por Yeltsin. Así, hay que relativizar el impacto del discurso nacional-bolchevique sobre la sociedad rusa, una sociedad que rechaza la violencia y no espera mucho de los políticos. Yeltsin se equivocó, como los politólogos, cuando se lanzó en la guerra contra Chechenia para robarle la bandera nacionalista a la oposición. Los rusos no quieren a los chechenos, pero tampoco les interesa hacerles la guerra. 
¿EXTREMA DERECHA EN RUSIA?

Muchos pueden tener nostalgia por la URSS, hasta la esposa de Yeltsin, pero el nacionalismo no es una buena apuesta política. A la gente le importa de verdad la situación económica y social, los salarios y las pensiones, la corrupción y la violencia. El nacionalismo no presenta un peligro mayor, si uno considera los pequeños grupos que se reclaman de él, pero no deja de ser preocupante en la medida en que aumenta su influencia dentro de los grupos dirigentes.

¿Se puede hacer pronósticos? Según Alexander Gorianin "Dios no manda la peste dos veces", después de la dictadura comunista, Rusia no conocerá la dictadura nazi. ${ }^{54}$ Los grupos son pequeños y marginales, sin base social; expresan una crisis de jóvenes, son frutos de la libertad como el Heavy Metal y los Skinheads, pero también como el paganismo, el esoterismo, los shamanistas, los Hare Krishna. No tienen dinero, no tienen grandes jefes ni aglutinan muchedumbres. Sin embargo, otros son menos optimistas, como Vladimir Lukov, del comité Fuerzas Armadas y Sociedad, quien piensa que Rusia se siente frustrada y humillada, por más que nadie le haya impuesto un 'diktat de Versalles'. Lukov opina que la crisis socio-económica golpea a las masas, que existen un lumpenproletariat, militares criminales y mercenarios disponibles. ${ }^{55}$

La incógnita es la convergencia posible entre los extremos. Ni Stalin ni Hitler volverán, pero sí quizá una nueva síntesis de populismo y de nacionalismo, con tonalidad religiosa, capaz de emocionar a las masas. No creo que un verdadero fascismo, menos aun un nacional-socialismo triunfe pronto en Rusia, pero sí creo en el peligro del surgimiento de un sistema autoritario fundado sobre el populismo nacionalista. En el cocktail pardo (negro) y rojo, hay muchas variantes posibles; lo único seguro es que Zyuganov no es Lenin, Zhirinovski no es Hitler, y no creo que Lebed sea Mussolini.

${ }^{54}$ Alexander Gorianin, "Bog Dvazhdy podriyad chumu ni nasilaet", Russkaya Mysl, 4144, 10 de octubre, 1996, p. 9.

${ }^{55}$ Vladimir Lukov, "Rusia no ha sido curada", Russkaya Mysl, 4157, 16 de enero, 1997. 